\title{
Characterization of a new small cell lung cancer (SCLC) cell line STP54 derived from a metastatic bioptate of a combined type of SCLC with Non-SCLC component
}

\author{
Tomasz Skirecki ${ }^{1,2}$, Grażyna Hoser1, Joanna Domagala-Kulawik², Jerzy Kawiak ${ }^{1}$ \\ ${ }^{1}$ Department of Clinical Cytology, Medical Center of Postgraduate Education, Warsaw, Poland \\ ${ }^{2}$ Department of Pneumonology and Allergology, Warsaw Medical University, Warsaw, Poland
}

\begin{abstract}
Small cell lung cancer constitutes $15-20 \%$ cases of lung cancers, currently the leading cause of death from malignant diseases. It also causes the demise of $>90 \%$ of affected individuals in 5 years. We have established a new SCLC cell line STP54 derived from fine needle aspirate of metastatic supraclavicular lymph node of 54 -year-old women for model experiments. The primary tumor was diagnosed by histopathological examination as combined type of small cell lung cancer with a non-small cell component. We cultured the cancer cells in the RPMI 1640 medium. In the long-term culture only the small cell component survived. The cell line was established after 30 passages and then characterized by performing cell morphology, cell growth analysis, tumorigenicity in vitro and flow cytometry analysis of selected markers (like NCAM, cytokeratines, HLA-ABC, Fas, Bcl-2, p53, CXCR4, CD210). The cells were growing in floating aggregates and show features suggesting its invasiveness. We suggest that this new cell line may serve as a valuable tool for further studies on lung tumor biology, molecular pathogenesis and metastatic mechanism.
\end{abstract}

Key words: small cell lung cancer (SCLC), cell line, monoclonal antibody, immunocytochemistry

\section{Introduction}

Small cell lung cancer (SCLC) constitutes about 15-20 per cent of all lung cancer cases and is strongly correlated with cigarette smoking [26]. It is characterized by a high growth rate, early and widely spread metastases, especially to lymph nodes, bone marrow and brain [1]. Despite initial sensitivity to chemotherapy in most cases, SCLC almost inevitably relapses, more than $95 \%$ of patients eventually die of cancer [9]. More than $90 \%$ of SCLC cases are the typical SCLC. The remaining are recognized as combined SCLC with non-small cell lung cancer (NSCLC) component [20].

The treatment of SCLC, unlike NSCLC, usually involves chemo- and radiotherapy, surgical resection is rarely performed, mostly for patients with stage I limited disease [20]. For this reason, access to SCLC tumor specimens is limited for ex vivo experiments. Thus, establishing SCLC cell lines is essential for further studies on tumor biology and pathology.

Correspondence: J.Kawiak, Dept. of Clinical Cytology,

Medical Center of Postgraduate Education, Marymoncka Str. 99, 01-813 Warsaw, Poland; tel.: (+4822) 5693821,

fax.: (+4822) 5693829, e-mail: jkawiak@cmkp.edu.pl
In this paper, we describe the establishing and characterization of a new SCLC cell line derived from a combined small cell lung cancer with a non small cell component (SCLC/NSCLC) bioptate obtained from a supraclavicular lymph node metastasis.

\section{Materials and methods}

Patient history and biopsy specimen. A 54-year-old, smoking woman was admitted to the hospital due to enlarged opacity in the X-ray film of the upper mediastinum, reccuring fevers, cough and exertional dyspnoea. The patient gave a several months history of cough and pyrexia prior to hospitalization. Physical examination revealed palpable $3 \mathrm{~cm}$ supraclavicular tumor. CT scan revealed $10 \mathrm{~cm}$ mass in the right mediastinum, fusing with two others. On bronchoscopy micronodular lesions of the right brochi were present. Serum LDH concentration was markedly increased. In order to establish a diagnosis a fine-needle aspiration biopsy (FNAB) of supraclavicular lymph node was taken. The aspirate was split. One part was fixed in ethanol for cytological examintation and the other was placed in sterile physiological saline for culturing. The examination of FNAB smear in the light microscopy revealed cancer cells with the features of SCLC and NSCLC and finally combined type of SCLC was diagnosed. After completion of diagnosis the patient was discharged from the hospital in a good general condition and recommended for treatment in oncology center. 
Table 1. Expression of selected markers in the new STP54 cell line.

\begin{tabular}{|l|c|}
\hline \multicolumn{1}{|c|}{ Marker } & Per cent of positive cells \\
\hline Cytokeratin 19 & 98 \\
\hline NCAM/CD56 & 68 \\
\hline ILA-ABC & 2 \\
\hline l'as & 34 \\
\hline LMP-1 & 90 \\
\hline Bc1-2 & 12 \\
\hline P53 & 0 \\
\hline CXCR4 & 99 \\
\hline IT,-10R & 16 \\
\hline
\end{tabular}

Cell culture. The obtained aspirate from a fine-needle biopsy of supraclavicular lymph node was placed in sterile physiological saline and taken to a laboratory. Then it was placed in a $25 \mathrm{~cm}^{3} \mathrm{cul}-$ ture flask in RPMI-1640 (Gibco) medium supplemented with 10\% new-born calf serum (NCS) (Biochrom) and standard antibiotics, penicillin and streptomycin and kept at $37^{\circ} \mathrm{C}$ in a humidified atmosphere in $\mathrm{CO} 2$ incubator $\left(5 \% \mathrm{CO}_{2}\right)$. The culture medium was changed twice a week. After a month of culturing (10 passages) the cells were banked RPMI-1640 with $20 \%$ NCS and $10 \%$ DMSO and stored in liquid nitrogen. A few months later the cells were thawed out and re-cultured. After 30 passages, cells were considered an established cell line and then characterized.

Morphological studies. The tumor cells used to initiate the cell line were reviewed. For cytological examination of the cell line, cells suspension was centrifuged, and cells smear was done, fixed with Cytofix (Samko, Poland) and stained with HematoxylinEosin(H-E). The growth pattern of the established line was described under a phase-contrast microscope.

Growth studies. Kinetics in liquid culture was assayed in RPMI1640 medium with $10 \%$ heat-inactivated normal calf serum (NCS) supplemented with $1 \%$ penicillin/streptomycin in $25-\mathrm{mm}$ Petri dishes. Cells were placed into a dish, pipetted vigorously and counted in Burker hemocytometer. Cell counting was performed after $24 \mathrm{~h}, 48 \mathrm{~h}, 72 \mathrm{~h}$ and $96 \mathrm{~h}$.

Colony forming efficiency. The colony-forming efficiency was determined by suspending single cells in a semisolid methylcellulose medium (MethoCult H4230, StemCell Technologies). 5x103 cells per $25 \mathrm{~mm}$ Petri dish was used and colonies were counted after 7 days using phase-contrast microscope.

Flow cytometry. Cell surface staining was performed as described [17] Briefly, $30 \mu 1$ of cells suspension was labeled with $7 \mu 1$ of the monoclonal antibody of interest for $30 \mathrm{~min}$. at room temperature and then washed with $1 \mathrm{ml}$ of $2 \%$ serum in PBS and re-suspended in $300 \mu 1$ of $0.5 \%$ formaldehyde in PBS. Then, the probes were acquired to FACS Calibur flow cytometer (Becton-Dickinson, San Jose, California). The cells were collected by CELLQuest software. For the intracellular staining, cells were fixed in $4 \%$ formaldehyde for 20 min., washed in PBS, stored in $70 \%$ ethanol and permeabilized before further treatment by $0.1 \%$ NP- 40 in PBS for $30 \mathrm{~min}$. at room temp. After the permeabilization, the labeling was performed as for surface antigens.

The following monoclonal antibodies $(\mathrm{mAb})$ were used: antiCD56 (NCAM) FITC, anti-Fas(CD95) PE-Cy5 (BD Bioscience, San Jose), anti-Cytokeratin 19 (CK19) (Santa Cruz Biotechnolo- gy), MOC-1 (a generous gift from dr de Leji), anti-Bcl2 FITC, anti-EBV(anti LMP-1), anti-p53 FITC, (Dako Cytomation), antiHLA-ABC PE-Cy5, anti-CXCR4 PE, anti-CD210 PE. Fluorescently unconjungated $\mathrm{mAbs}$ were stained with Zenon Alexa Fluor 488 labeling kit (Molecular Probes), as previously desribed [6]. MOC-1 is IgG1 class monoclonal antibody recognizing NCAM/CD56 antigen.

\section{Results}

\section{Morphological studies}

Cytological examination of the $\mathrm{H}+\mathrm{E}$ stained smear of FNAB obtained from supraclavicular lymph node revealed mixed pattern. There was domination (about $80 \%$ ) of small cells with scant cytoplasm, ill-defined cell borders, finely granular nuclear chromatin, and absent or inconspicuous nucleoli. Nuclear smearing was visible. Apart from SCLC cells we found admixture of the cells with typical features of non- small cell type. There were anaplastic cells with well preserved cytoplasm however, without cell borders and with marked nuclear boarding and conspicuous nucleoli. The aggregates of these cells suggested adenocarcinoma. Interestingly, when the cultured cells underwent cytological examination after 30 passages, it occured that only small cell component of the starting material was present. The new STP54 SCLC cell line grew as relatively tightly packed floating aggregates, amorphous and irregular in shape. Some cells formed characteristic chains (Fig.1). This cell line fits type 2 growth pattern according to Carney et al. [7]. Under high magnification numerous cytoplasmic neurosecretory dense core granules could be seen (Fig.1)

\section{Growth kinetics and colony forming assay}

The cells were passaged 30 times before considered an established cell line, named STP54. However, this cell line has been cultured for even more than 60 passages. Growth kinetics was assessed by cell counting. The results were put on a chart which was used to calculate Population Doubling Time, by the 'best fit' method. The graph was described by $\mathrm{y}=-141.85+361.4 \mathrm{x}-$ $223.47 x^{2}+60.879 x^{3}$. The calculated PDT was $68 \mathrm{~h}$.

Colony forming efficiency of the STP54 cells reached $0.72 \%$.

\section{Immunocytochemical characterization of STP54}

The expression of selected markers, analyzed by flow cytometry is summarized in Table 1. and Fig. 2. STP54 expressed high level of Cytokeratin19, which is a marker of lung epithelial cells and lung cancers. Also, Neural Cell Adhesion Molecule was detected by MOC-1 antibody in most of the cells. Both of these molecules are characteristic for the classic SCLC. 

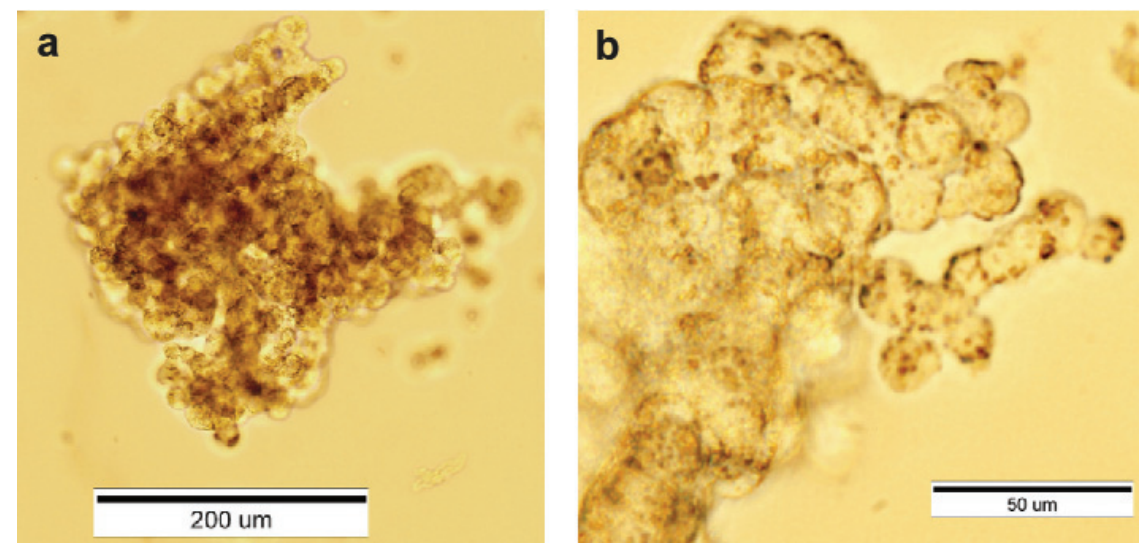

Fig. 1. STP54 cells form floating aggregates (a). Numerous intracellular granules can be seen, especially under the stronger maginification (b).
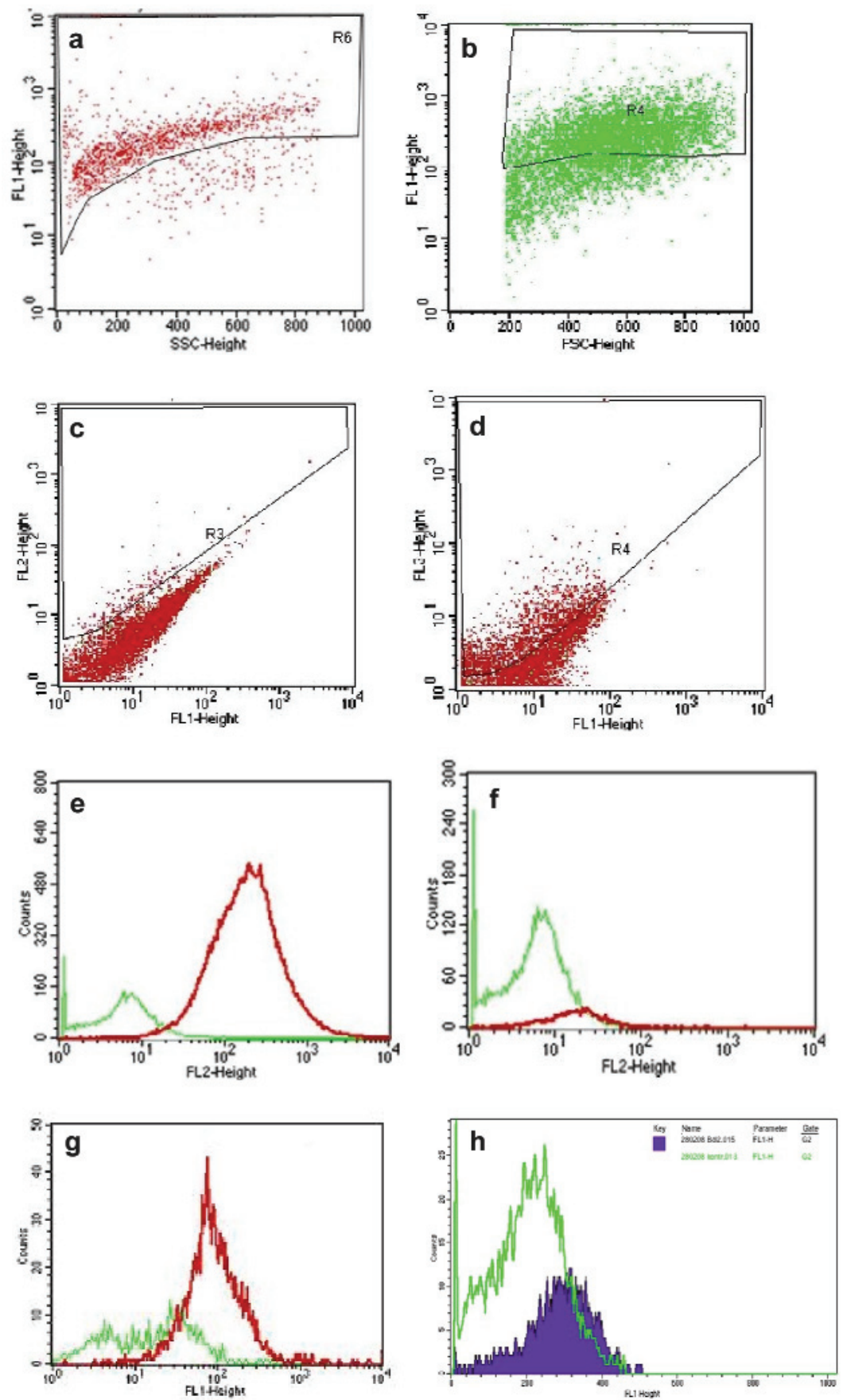

Fig. 2. Immunophenotyping of the new STP54 cell line by flow cytometry analysis. Cells positive for the selected markers are gated in the cytograms (a-d). Histograms show the fluorescence intensity of cells labeled with specific mAbs in red and purple and controls in green. (a) Cytokeratin 19, (b) NCAM, (c) HLA-ABC, (d) Fas, (e) LMP-1, (f) IL-10R, (g) CXCR4, (h) Bcl-2. 
Expression of HLA-ABC was low. Infection by Epstein-Barr Virus was found by the expression of Latent Membrane Protein 1. P53 tumor suppressor protein was not detected by immunocytochemistry, while low expression of Bcl-2 oncogene was noticed. Additionally, almost all cells were positive for the chemokine CXCR4 receptor and a significant subpopulation expressed the Fas receptor and for interleukin10 receptor (CD210). The composition of the cell line population suggests the heterogeneity of cells.

\section{Discussion}

Combined small cell lung cancer with non-small cell component is a rarely occurring lung tumor which is thought to be characterized by more aggressive clinico-pathologic behaviour than histologically pure tumors [22]. Here, we present a cell line derived from a 54-year-old woman who was diagnosed with SCLC/NSCLC (stage IV, extensive disease). At the admission the patient presented typical symptoms, and the radiological pattern of SCLC. The diagnosis was based on the cytological examination of a fineneedle biopsy-derived specimen. Several studies have reported successful establishment of SCLC cell lines in a chemically defined medium such as HITES or ACL-3 with a high efficiency (up to 70\%) [7,21]. However, other studies reveal that cell lines derived in such conditions are unable to grow for a long periods of time, indicating that the serum supplementation is required for establishing permanent cell lines [25]. Unfortunately, under such conditions the efficiency of establishing cell lines reaches maximally 10 per cent $[2,12]$. We attempted successfully to establish cell line in a serum-supplemented growth medium and after 30 passages we have regarded the cells as an established cell line. Up to the present, the cells have been cultured for more than 7 months. Of interest, repeated cytological examination of the cultured cells revealed the presence of small cell lung cancer only. Morphologically, the cells formed floating clusters, a typical growth pattern of SCLC in the liquid milieu. The population doubling time of this line reached 68 hours and is within the range of other reported SCLC cell lines [7]. Also, the colony forming efficiency, which is 0.72 per cent, is similar to those described previously [14].

Analysis by immunofluorescence staining using monoclonal antibody to CK19 showed positive staining for human cytokeratin, verifying the epithelial origin of this tumor [4]. MOC-1 also binds to the NCAM molecule confirming the SCLC diagnosis [5,11]. Reduced proportion of Fas receptor expression cells is known to exist in some cancers, including lung cancers. The low Fas expression is probably one of the main strategies developed by tumor cells to avoid apoptosis induced by activated $\mathrm{T}$ cells producing FasL [15]. Another molecule that is extremely important in the immunosurveillance mechanisms is the HLA-ABC (major histocompatibility complex class I). HLA-ABC enables recognition of mutated and virus-infected cells by the immune system. It was shown that low expression of this molecule on cancer cells is correlated with the poor prognosis due to numerous metastases and clinical aggressiveness $[10,13]$. We found very poor expression of HLA$\mathrm{ABC}$ on the STP54 cell line, which might be responsible for fast clinical progress and metastases found in the patient.

Aside from the "classic" antigens, we have also checked the expression of CXCR4, a chemokine receptor for the Stromal-Derived Factor-1 (SDF-1). The STP54 cell line shows a high positive staining for CXCR4, what confirmes the presence of this receptor in SCLC [6]. The CXCR4/SDF-1 axis is often thought to be a key mechanism responsible for cancer metastasis [18]. This notion might be right also in this case, as the cells were aspirated from a metastatic site localized in a lymph node. Another receptor that was detected on a subpopulation of the STP54 cells was CD210, a receptor for interleukin 10. The role of this cytokine in SCLC has not been described, however there are some contradictory papers of its impact on NSCLC $[22,23]$. Latent Membrane Protein-1 (LMP-1), a molecule characteristic for Epstein-Barr Virus infection was found on the STP54 cells. EBV is often regarded as an oncogenic factor, but the significance of LMP-1 in lung cancers is uncertain and requires further investigation [8].

Numerous mutations in the p53 gene are known in SCLC. Introduction of the wilde-type p53 cDNA into SCLC led to growth inhibition and chemosensitivity [24]. These observations, together with the absence of $\mathrm{p} 53$ by immunocytochemistry in our tests in the STP54 cells, might suggest chemoresistance. On the other hand, Bcl-2, another factor known to be responsible for chemoresistance in SCLC [19,27], was expressed in low proportion of our new cell line. Altogether, those facts suggest the existence of several different ways of chemoresistance developed by SCLC.

In conclusion, we have successfully established a new small cell lung cancer cell line, which we named STP54. We have characterized it by the growth properties, morphology, immunocytochemical expression of selected antigens and sensitivity to cisplatin. This cell line will be used in the future to study the tumor biology and to develop new therapeutical strategies.

Acknowledgements: Supported by grant from Medical Centre of Postgraduate Education, Warsaw, 2006/2007. 


\section{References}

[1] Argitis A, Murren JR. Staging and clinical prognostic factors for small-cell lung cancer. Cancer J. 2001;7:437-447.

[ 2] Bepler G, Koehler A, Kiefer P, Havemann K, Beisenherz K, Jaques G, Gropp C, Haeder M. Characterization of the state of differentiation of six newly established human non-smallcell lung cancer cell lines. Differentiation. 1988;37:158-171.

[3] Bojarska-Junak A, Roliński J, Kawiak J. Modification of immunocytochemical ZAP-70 assay for potential clinical application In B-cell chronic lymphocytic leukemia. Folia Histochem Cytobiol. 2005;43:19-23.

[4] Broers JLV, Ramaekers FCS, Rot MK, Oostendorp T, Huysmans A, van Muijen GNP, Wagenaar SS, Vooijs GP. Cytokeratins in Different Types of Human Lung Cancer as Monitored by Chain-specific Monoclonal Antibodies. Cancer Res. 1988;48:3221-3229.

[ 5] Broers JLV, Rot MK, , Oostendorp T, Huysmans A, Wagenaar SS, Wiersma van Tilburg AJM, Vooijs GP, Ramaekers FCS. Immunocytochemical Detection of Human Lung Cancer Heterogeneity Using Antibodies to Epithelial, Neuronal, and Neuroendocrine Antigens. Cancer Res. 1987;47:3225-3234.

[6] Burger M, Glodek A, Hartmann T, Schmitt-Graff A, Silberstein LE, Fujii N, Kipps TJ, Burger JA. Functional expression of CXCR4 (CD184) on small-cell lung cancer cells mediates migration, integrin activation and adhesion to stromal cells. Oncogene. 2003;22:8093-8101

[7] Carney DN, Gazdar AF, Bepler G, Guccion JG, Marangos PJ, Moody TW, Zweig MH, Minna JD. Establishment and Identification of Small Cell Lung Cancer Cell Lines Haing Classic and Variant Features. Cancer Res. 1985;45:2913-2923.

[ 8] Chen FF, Yan JJ, Lai WW, Jin YT, Su IJ. Epstein-Barr virusassociated nonsmall cell lung carcinoma: undifferentiated "lymphoepithelioma-like" carcinoma as a distinct entity with better prognosis. Cancer. 1998;82:2334-2342.

[9] Chute JP, Chen T, Feigal E, Simon R, Johnson BE. Twenty years of phase III trials for patients with extensive-stage small-cell lung cancer: perceptible progress. J Clin Oncol. 1999; 17:1794-1801.

[10] Concha A, Esteban F, Cabrera T, Ruiz-Cabello F, Garrido F. Tumor aggressiveness and MHC class I and II antigens in laryngeal and breast cancer. Semin Cancer Biol. 1991;2:4754.

[11] De Leij L, Poppema S, Nulend JK, ter Haar A, Schwander E, Ebbens F, Postmus PE, The TH. Neuroendocrine differentiation antigen on human lung carcinoma and Kulchitski cells. Cancer Res. 1985;45:2192-2200.

[12] Duchesne GM, Eady JJ, Peacock JH, Pera MF. A panel of human lung carcinoma lines: establishment, properties and common characteristics. Br J Cancer. 1987;56:287-293.

[13] Esteban F, Concha A, Delgado M, Pérez-Ayala M, RuizCabello F, Garrido F. Lack of MHC class I antigens and tumor aggressiveness of the squamous cell carcinoma of the larynx. Br J Cancer. 1990;62:1047-1051.

[14] Gazdar AF, Carney DN, Nau MM, Minna JD. Characterization of Variant Subclasses of Cell Lines Derived from Small
Cell Lung Cancer Having Distinctive Biochemical, Morphological, and Growth Properties. Cancer Res. 1985;45:29242930.

[15] Gormus U, Ergen A, Yaylim-Eraltan I, Yilmaz H, Turna A, Bozkurt N, Isbir T. Fas-1377 A/G polymorphism in lung cancer. In vivo. 2007;21:663-666.

[16] Hatanaka H, Abe Y, Kamiya T, Morino F, Nagata J, Tokunaga T, Oshika Y, Suemizu H, Kijima H, Tsuchida T, Yamazaki $\mathrm{H}$, Inoue $\mathrm{H}$, Nakamura $\mathrm{M}$, Ueyama Y. Clinical implications of interleukin (IL)-10 induced by non-small-cell lung cancer. Ann Oncol. 2000;11:815-819.

[17] Hoser G, Wasilewska D, Domagała-Kulawik J. Expression of Fas receptor on peripheral blood lymphocytes from patients with non-small cell lung cancer. Folia Histochem Cytobiol. 2004;42:249-252.

[18] Hu J, Deng X, Bian X, Li G, Tong Y, Li Y, Wang Q, Xin R, He X, Zhou G, Xie P, Li Y, Wang JM, Cao Y. The expression of functional chemokine receptor CXCR4 is associated with the metastatic potential of human nasopharyngeal carcinoma. Clin Cancer Res. 2005;13:4658-4665.

[19] Ikegaki N, Katsumata M, Minna J, Tsujimoto Y. Expression of bcl-2 in small cell lung carcinoma cells. Cancer Res. 1994;54:6-8.

[20] Jackman DM, Johnson BE. Small-cell lung cancer. Lancet. 2005;366:1385-1396.

[21] Masuda N, Fukuoka M, Takada M, Kudoh S, Kusunoki Y. Establishment and characterization of 20 human non-small cell lung cancer cell lines in a serum-free defined medium (ACL-4). Chest. 1991;100:429-438.

[22] Ruffini E, Rena O, Oliaro A, Filosso PL, Bongiovanni M, Arslanian A, Papalia E, Maggi G. Lung tumors with mixed histologic pattern. Clinico-pathologic characteristics and prognostic significance. Eur J Cardiothorac Surg. 2002;22: 701-707.

[23] Soria JC, Moon C, Kemp BL, Liu DD, Feng L, Tang X, Chang YS, Mao L, Khuri FR. Lack of interleukin-10 expression could predict poor outcome in patients with stage I nonsmall cell lung cancer. Clin Cancer Res. 2003;9:1785-1791.

[24] Stahel RA, Weber E. Small Cell Lung Cancer: The new biology. Semin Radiat Oncol. 1995;5:11-18.

[25] Sugaya M., Takenoyama M., Osaki T., Yasuda M., Nagashima A., Sugio K., Yasumoto K. Establishment of 15 Cancer Cell Lines From Patients With Lung Cancer and the Potential Tools for Immunotherapy. Chest. 2002;122:282-288.

[26] Tyczyński JE, Bray F, Parkin DM. Lung cancer in Europe in 2000:epidemiology, prevention and early detection. Lancet Oncol. 2003;4:45-55.

[27] Zangemeister-Wittke U, Schenker T, Luedke GH, Stahel RA. Synergistic cytotoxicity of bcl-2 antisense oligodeoxynucleotides and etoposide, doxorubicin and cisplatin on smallcell lung cancer cell lines. Br J Cancer. 1998;78:1035-1042.

Submitted: 3 July, 2008 Accepted after reviews: 11 October, 2008 